\title{
A Pedagogical Approach to Detective Fiction
}

\author{
Agustín Reyes-Torres \\ Universitat de València, Facultad de Magisterio \\ Departamento de Didáctica de la Lengua y la Literatura \\ Primer piso - Despacho $\mathrm{n}^{\circ} 6$ \\ Avenida dels Tarongers 4, 46022 Valencia, Spain \\ Tel: 34-963-864-072 / 34-646-402-826 E-mail: agustin.reyes@uv.es
}

\author{
Received: November 22, 2011 \\ Accepted: November 28, $2011 \quad$ Published: December 1, 2011 \\ doi:10.5539/ies.v4n5p33 \\ URL: http://dx.doi.org/10.5539/ies.v4n5p33
}

\begin{abstract}
One of the main concerns when teaching a foreign language is how to encourage students to read and become interested in its literature. This article presents detective fiction as a pedagogical tool that provides the key elements to make it appealing for young readers. In this way, the mystery, the action and the suspense in the story; the figure of the detective; or the fact that the end of the story is always morally acceptable turn this literary genre in a magnificent reading to practise the target language and explore the social and cultural issues portrayed. The aim of my work is to present a series of activities related with the detective fiction of international writers such as Sir Arthur Conan Doyle, Francisco González Ledesma, Abdelilah Hamdouchi and James McClure that demonstrate the pedagogical value and practical use of detective fiction.
\end{abstract}

Keywords: Detective fiction, Literature, Multicultural, Pedagogical value

\section{Introduction}

Recent articles on the teaching of literature address two main questions: How can teachers enable and encourage more students to read literature today? What can teachers do to increase the likelihood that more language students will become lifelong readers of literature? (Nance, 2010). A good answer to both of these questions is the use of detective fiction in the foreign language classroom. Currently, detective fiction is one of the most globalized, most popular, and best selling of commercial literary genres. Many students find it appealing due to the mystery, the action and the suspense in the story; or maybe it is due to the figure of the detective, or the fact that the end of the story is always morally acceptable. One way or the other, all these elements provide a superb opportunity to use detective literature as a pedagogical tool in the Foreign Language class to practise the target language, be it English or Spanish (or any other language), and to explore issues of cultural interaction and a diverse range of significant historical and political moments in different countries all over the world.

Detective fiction's current integration of multicultural social concerns occurs frequently in the plot, the setting, the characters or the criminal investigation. Sir Arthur Conan Doyle, for instance, presents a renowned Sherlock Holmes who rationally solves all kind of mysteries but who also enjoys a very particular lifestyle and displays an interesting outlook of British society that could provide excellent cultural material for discussion. In the same way, Inspector Ricardo Méndez, the detective created by the Spanish writer Francisco González Ledesma, is an old and unusual policeman who has been patrolling the streets of Barcelona for almost 30 years. He shows the social and cultural changes that the city has undergone in the first decade of the $21^{\text {st }}$ Century. Like him and like Holmes, there are other detectives all over the world that illustrate the many ways in which cultural diversity is posed by international writers. Some of these could be Abdelilah Hamdouchi in Morocco, James McClure and Deon Meyer in South Africa, HRF Keating in India, Robert van Gulik in China and Walter Mosley in the United States.

\section{Pedagogical Value and Educational Goals of Detective Fiction}

These writers have used the hardboiled detective story and the hardboiled hero to make powerful statements about the reality in which they are immersed. Thus, as their novels move through the investigation of a serious crime, their work combines three educational goals for the literature course in the Foreign Language classroom: the development of individual mind, for which students must reflect critically on ethical, intellectual and aesthetic models; a knowledge of other cultures which, by comparison, invites students to explore and consider other cultural values and 
traditions different from theirs; and the development and practice of language skills while reading, discussing and writing about the different literary works.

Teachers from high schools through universities are carrying out curricular reforms which will allow them to keep up with the changes in the teaching approaches to second language acquisition, and they are looking for didactic materials to discuss social and cultural issues. Detective fiction, in this respect, provides one striking option. The aim of this article is to present a selection of detective novels and short stories that may demonstrate the pedagogical value and practical use of this literary genre.

To start with, a good introduction to detective fiction could easily be done through a study of the figure of Sherlock Holmes. It is likely that some students have already heard of him and have even read some of his adventures previously. The teacher should show them some pictures of him as represented in popular culture to prompt them to talk about him and see how much they know about this emblematic character. Visual stimuli, in this case, can be of use as it would help students realize how Holmes is a rather popular figure. A similar task could be done with other well-known detective heroes such as Agatha Christie's Miss Marple or Raymond Chandler's Philip Marlowe. The initial objective is to make students feel somewhat acquainted with the topic. For this purpose, it would also be recommended to show other photos of other detectives on popular TV series such as Jessica Fletcher from Murder, She Wrote, Dale Cooper from Twin Peaks or Horatio Cane from CSI Miami. The novels and the TV series in which all these detectives appear revolve around the investigation of a crime or mystery and students normally find both the story's plot and the character appealing.

\section{Classic Detective: Sherlock Holmes and "The Three Students"}

As with the reading of any other literary work, to start working on it, the teacher should carry out an introduction to the author and the story. In this case, Conan Doyle's story selected, "The Three Students", comes from the collection The Return of Sherlock Holmes (1903) and is only six pages long, so that the length can facilitate the reading for any intermediate-level reader. Given that Conan Doyle's work has been widely translated, this reading could be done in English by English learners or in Spanish by Spanish learners, depending on the teacher and the target language. An example of the pre-reading questions could be:

a) What does the title of the story suggest? How could it be related to a mystery that Sherlock Holmes has to investigate?

b) What are some of the most famous universities in the United Kingdom?

c) Imagine the students that attended these universities at the end of the $19^{\text {th }}$ Century. What do you think they were like?

d) If you were given the opportunity to obtain the question for an exam the night before you take it, what would you do? Would you cheat?

Since the story of "The Three Students" deals with college life and the case in which Holmes gets involved is an academic issue, students should easily relate to it. While the students should do the actual reading at home, the discussion should take place in class. Its content would probably trigger moral and cultural questions. Among others, the objectives of this unit are to foster reading, individual reflection and later class work.

The post-reading questions would be aimed at checking the students' comprehension skills and then at engaging them in a further discussion. Some of these questions could be:

a) Who demands Sherlock Holmes' help to investigate a crime? Why?

b) Where did the crime take place? Who is the suspect?

c) As a reader, could you figure out how to solve the crime?

d) Is there a moral in the story? What is it?

These types of questions could be applied to any kind of classic detective fiction. Moreover, more time could also be spent discussing the historical context, the portrayal of society and the social classes, the concept of honor and the old emphasis of the university academic curriculum on the study of Greek.

\section{Inspector Méndez in Contemporary Spain}

From the reading of a classic literary work like Sherlock Holmes, we would move on now into the noir or hardboiled novel, a detective fiction subgenre that has its origins in the United States but that has quickly spread in many countries in the last decades. This type of story is more urban and focuses not only on the crime but on the social aspects that surround it. Normally, it represents a strong critique of society in which the boundary between good and evil is not easily discernible. In this way, González Ledesma's books with Inspector Méndez as the protagonist 
constitute an enjoyable and relevant reading experience for learners of Spanish as a second language. They are a remarkable representation of cultural and social matter in contemporary Spain and, once again, it would be recommended to start with short stories since the main goal is to have students engage in their work and make them feel capable of doing it.

Méndez (2006) consists of twenty-two short stories in which the eponymous protagonist is an uncommon detective difficult to typify. He doesn't believe in the law, but he believes in street justice. A survivor of another era, honest and skeptical, he has been hardened by the slums of Raval, the bourgeois name given by the Health Inspectors to the old Red Light District (Barrio Chino) of Barcelona. Méndez is a street dog and street dogs do not follow orders. However, he characterizes himself for his humanity. The language of the book, although occasionally coarse, mixes tenderness and lyricism with doses of irony and humor. Unfortunately, González Ledesma's work has not been translated, so this reading could only be done in the Spanish language class.

Two accessible short stories could be "El arte de mentir" and "La serpiente vieja". As with the unit on Sherlock Holmes, every story should be preceded by a pre-reading activity and followed by a post-reading one. For "La serpiente", a possible list of questions could be:

a) Discuss the title. Do you think it could refer to Méndez? How?

b) Describe the characteristics of a snake. Why is it important that the snake is old?

c) In your opinion, is justice subjective or objective? Expand.

This story deals with Méndez's personal conflict between solving a case using the law, that is, taking the criminal to court, or alternatively, using street justice. The reading comprehension and discussion could be based on the following questions:

a) Why do you think Méndez pays the bail to let the rapist get out of jail?

b) What is Méndez's boss reaction?

c) In your opinion, is Méndez a compassionate or a corrupted cop?

While reading this story, the Spanish learner might notice the contrast between Sherlock Holmes and Méndez, between the classic detective novel and the noir, and between Conan Doyle's and González Ledesma's writing style. It is probably a good moment to discuss these differences and study their distinctive features in more depth.

\section{Abdelilah Hamdouchi: Multicultural Detective Fiction in Morocco}

Although traditionally, there has been little attempt to read detective fiction in relation to the Foreign Language class, it is evident that due to the widespread exposure that this literary genre has had in the last decades, it definitely offers a wide range of opportunities as pedagogical material, especially in English. Detective novels are considered familiar, accessible, and unthreatening by readers who might be resistant to other texts. Also, much contemporary detective fiction explores issues of cultural interaction, race, class, gender and ethnicity. In this respect, the detective genre shows that the process of literary globalization is evident. However, it also demonstrates that globalization does not produce a homogeneous type of detective novel. Interestingly enough, the same conventions, disseminated and shared all around the world, produce very distinct results (Hardt, 2002). Every author in every country is distinguishable from another due to the local aspects that differentiate his or her work. As a result, one can conclude that while detective fiction writers maintain the same formula in their plots, their literary works reflect significant differences as far as the fictional world they depict. Homogenization thus becomes heterogeneous, which is the multicultural aspect that can be explored for a didactic purpose.

In order to illustrate this idea, this paper will now focus on two detective novels: The Final Bet (2001), and The Song Dog (1991), and on how they can be approached from a pedagogical perspective to be used in the foreign language class. In this case, the teaching goal shifts towards the development of the students' reading and analysis skills, so an upper-intermediate or advanced level of English would be expected.

Written by Abdelilah Hamdouchi, The Final Bet (2001) deals with the murder of a rich elderly French woman named Sophia who lived in Casablanca, Morocco, in the late 1990s. The main suspect is the woman's husband, a Moroccan man named Othman, who is over forty years her junior; the motive is explained as being that Othman would be the sole beneficiary to Sofia's estate should she die, and the reader does not know until the end of the story whether he is the real murderer or not. Throughout the course of the novel, aspects of Moroccan life highlight the fear of authority and the inconsistency among the police procedures that are a mainstay in the country. The murder of a French woman receives more attention than if a Moroccan woman had been killed, and the police consider Othman, a Moroccan man, a suspect while refusing to look elsewhere, which illuminates the unfair treatment and discrepancy among ethnicities. 
As with any good detective novel, as the story goes by, the reader is presented with a victim, a weapon, a clear motive, a suspect and, in this case, several detectives. But there is much more than that. Students would also learn about Morocco, its culture and its history and its idiosyncrasies. Because Morocco was colonized by the French, that culture still plays a very strong role in Moroccan life, largely because most of the population still speaks French and France is still regarded as a higher culture and thus a model to follow. In the same way, Morocco also appears to have an uncertain idea of what it is supposed to be as a country, due to so much outside influence. Morocco is in the Northern part of Africa, but is rejected by other African nations that claim that Morocco is not African enough. Morocco is only a couple of miles from Spain, and has had a lot of European influence through colonialism, but it is not considered European, either. The majority of Morocco's population is Muslim, which is considered a Middle Eastern characteristic, but the Middle East does not claim them, either. In conclusion, Morocco is a cultural identity in and of itself which is currently in the process of change.

Before the reading, and in order to have students reflect on the importance of the setting in which the novel takes place, the following questions could be of use.

a) If you were to write a detective novel in Morocco, in what city would the investigation take place?

b) What would be the characterization of the detective?

c) Who would be the victim? And the criminal?

d) Would there be any foreigners involved?

e) Would there be good guys and bad guys? Who are they?

f) What cultural issues could be included?

Throughout the literary analysis, we will see how the detective figure in The Final Bet is not a typical sleuth; he is a lawyer by the name of Ahmed Hulumi, and he uses his knowledge of the legal system to devise a plan to make the police see that there are other possible alternatives to Othman being the murderer. Hulumi uses qualities that mix both classic detective fiction and hardboiled detective fiction. It is classic in the way that he deduces the needed information from clues, and it is hardboiled because he gets involved in the action and goes to investigate areas where he is not technically supposed to go. In this way, he is the epitome of the change which is coming to Morocco: he is classically trained as a lawyer under the Arab track, but he commends Western police methods because they assume that a person is innocent until proven guilty, whereas in this area of the world, a man is guilty unless he can be proven innocent. Hulumi represents a new Moroccan generation that demands justice and democracy.

In contrast, Hamdouchi portrays the remnants of past political rule through Moroccan police and Detective Alwaar. We learn that the latter was trained in a time when "slapping [and] kicking a suspect or sending them down to the torture room" (p.16) was just part of the job. Significantly, now that he is not allowed to do so, Alwaar complains that this "transitional period makes [him] feel out of place" (p.16). Hamdouchi does an excellent job in this novel of portraying how the state of authority needs to be reformed in order to accommodate the basic rights of a human being. He uses detective fiction to denounce important social and political issues in Morocco such as how a lawyer should be able to be present during police questioning to avoid bribing and torture, to avoid, that is, the old colonial ways.

Some questions for the students to trigger the subsequent discussion could be:

a) A fundamental condition of the multicultural novel is that it represents speaking subjects in a field of multiple discourses. Culture must be understood as an open-ended, creative dialogue of subcultures, of insiders and outsiders, of diverse factions. Focusing on the characters, explain how this novel can be considered a multicultural detective novel.

b) The novel constitutes a dialogical interplay of voices: Sofia, Othman, Naeema, Detective Alwaar, Jacques, Hulumi, Boukrisha and Asila, Monsieur Bernard, the Commissioner, Selwa, Tharya, Othman's parents. Explore the representation of the different characters, their social roles and perspectives.

c) Who are the intended readers of this book? Justify your answer.

d) In what ways does Othman represent or not the typical Moroccan man?

e) Discuss the different ways in which the writer creates suspense throughout the first chapters.

f) Discuss the writer's representation of Othman's parents. In your opinion, why doesn't the father believe his son? 
g) Moroccan society is changing slowly and adopts France as a model to follow. France represents a modern and civilized society. However, in this novel, the killer is a French man. What does this contradiction symbolize? What does the fictional murder performed in the novel say about Western culture?

\section{James McClure's Novels: Postcolononial Detective Fiction in South Africa}

The next novel to study for a didactic purpose is The Song Dog (1991), by South African writer James McClure, in which he portrays the disturbing effects of colonialism. South Africa was ruled under the peculiar system of apartheid for over fifty years. Under this system, racial segregation was legalized and endorsed (Walder, 1998). The people of South Africa were divided into three different groups: white, black, and colored. James McClure's detective series depict South Africa during apartheid rule, specifically during the 1960's and 1970's. He uses detective fiction to bring to light the unfairness of apartheid rule.

Due to the relevance of the subject, this novel should be introduced with some basic explanation on postcolonial literature and a discussion on the topics of discrimination, racism and the legal culture of prejudice that existed in South Africa. Some questions for the pre-reading activity could be:

a) Postcolonial criticism seeks to understand the ideological forces (political, social, psychological issues) that pressed the colonized to internalize the colonizers' values. On the other hand, it also studies the resistance of colonized people against their oppressors (Tyson, 2006). How would you feel if your country was suddenly colonized? How would you react?

b) Why do you think that James McClure chose detective fiction as the literary framework to write his novels?

c) In this novel, there is a white detective and a black detective that are forced to work together. What kind of relationship do you think they have?

a) Read and comment on the following rules that the "Legal culture of prejudice" endorsed in South Africa (Lookwood, 1983, p.458):

- It is impermissible for a white to criticize a fellow white in front of a nonwhite.

- It is impermissible for whites to engage in sexual activities with nonwhites.

- Nonwhites are required to be deferential towards whites.

- Whites should lump all nonwhites into categories and not distinguish individual characteristics.

- Nonwhite homicide victims are to be given a lower priority than white homicide victims.

- Black police officers are not permitted to interrogate white suspects.

In this novel, the tag team of detectives are named Tromp Kramer and Mickey Zondi. These two men represent extreme opposites in South Africa's apartheid society, and yet have managed to form a team based on respect and camaraderie. Tromp Kramer is an old school Afrikaner who admits to being unfair, and yet knows that his job requires him not to make assumptions based on class, color, or religious belief. He is appealing as a character, however, because he is smart, dedicated to his work, and has an earthy appeal that sets him apart from the rest of society. When a person talks to him you know he is not going to soften his speech to make them feel more comfortable; he is going to tell it like it is and leave them to deal with it.

On the other hand, Mickey Zondi is an interesting contrast to Kramer's bluster. Zondi too has a well-developed sense of humor, and he is gifted intellectually with a photographic memory, an astounding command of languages, and a double consciousness from which he can glean information from both sides of South African society, the colonizer and the colonized. Zondi is a black Zulu native that was educated in a Catholic school, has worked in a white man's house as a servant, and now works on the Trekkersburg Police Force. He is informed of the white man's way of life, and at the same time is able to bridge the gap between being aware of white culture and being a member of black society. He is able to ascertain information and go to places where a typical white police officer would not be able to go. In Mickey Zondi's case, his cultural hybrid nature has benefitted him significantly. He is the more settled of the two detectives, content to have a family and spend time with them, which is something Kramer could never let himself do because his life is his work.

An interesting aspect to observe in The Song Dog is how, although Kramer has his biases and reinforces the traditional view on the superiority of the white men, his attitude towards Zondi gradually changes after they meet and start working together. While he must play the part of the superior when the two are in public, in private he feels comfortable calling Zondi by his first name instead of using the derogatory term kaffir; the two men joke with each 
other, share cigarettes, and share feelings. This kind of relationship between a white man and a black man would have been completely taboo during apartheid, but out of mutual respect for each other they maintain a friendship, regardless of social norms. This turns out to be the key for the success in their investigation. On a different level, it can also be read as McClure's personal hope for the end of racism in South Africa.

Reading questions for the students' discussion could be:

a) Discuss the mysterious initial references to the title of the novel. What do they mean?

b) The words and actions of the characters have a strong relevance in this novel and they mean more to us than the character themselves. Discuss how the words and actions in chapter 20 are significant in the representation of Kramer and Zondi.

c) Discuss the importance of Zondi's appearance for the development of the investigation.

d) Important to the understanding of the Kramer-Zondi relationship is what is not said. In your opinion, why are certain things not said? Explore what is "not said or done" in The Song Dog.

Finally, it is necessary to note that in the two novels discussed, both authors stick to typical detective conventions by not having the murderer be the first suspect. In Hamdouchi's The Final Bet the murder is committed in Morocco, but it is of one French person by another. Likewise, in McClure's work the murder is actually part of a serial killing by a psychopathic Afrikaner policeman. It is the colonizers who commit the crimes in both of these post-colonial locations. The violence inherent in the colonial system has been carried over, creating people who commit atrocious acts. The use of detective fiction allows Abdelilah Hamdouchi and James McClure to entertain as well as engage pertinent social issues in a critical way.

\section{Conclusion}

To conclude, one last activity based on the detective fiction that the students have read can be to ask them to imagine a situation in which Sherlock Holmes, Detective Alwaar, lawyer Hulumi, Tromp Kramer and Mickey Zondi meet up for dinner. The goal for them is to be creative and imagine what kind of conversation they would have. They could discuss their cases, their concept of justice or their cultural differences. Students would thus have the opportunity to enjoy themselves using these texts as a didactic tool to put into practice their language skills.

The reading and analysis of these detective novels by four different authors, Donan Coyle, González Ledesma, Abdelilah Hamdouchi and James McClure, demonstrate how detective fiction constitutes an attractive introduction to other cultures and an extraordinary material to be used in the Foreign Language class. Through identifications with the characters and the understanding of the social concerns represented, readers can experience something of the conflicts that Holmes, Othman, or Zondi face and reflect on how those conflicts vary according to different cultural outlooks and expectations. Their stories thus provoke discussions of crucial issues and the examination of the depiction of society by writers of different countries.

\section{References}

Conan Doyle, Sir A. (2007). The return of Sherlock Holmes (1903). London: Headline Book Publishing.

González Ledesma, F. (2006). Méndez. Barcelona: Almuzara.

Hamdouch, Abdelilah. (2008). The final bet. Cairo: American University Press.

Hardt, M., \& Negri, A. (2002). Imperio. Buenos Aires: Paidós.

Lockwood, B. B., Jr. (1983). A Study in Black and White: The South Africa of James McClure. Human Rights Quarterly, 5 (4), 440-466. http://dx.doi.org/10.2307/762230

Nance, K. A. (2010). Teaching literature in the languages. Boston: Prentice Hall.

McClure, J. (1992). The song dog. New York: Warner Books

Tyson, L. (2006). Critical theory today. A user-friendly guide. New York: Routledge.

Walder, D. (1998). Post-colonial literatures in English: History, language, theory. Malden, MA: Blackwell Publishers. 